\title{
Relações entre P\&D, patentes e exportação em empresas brasileiras ativamente inovadoras
}

\section{Relationships between $R$ \& D, patents and export actively innovative Brazilian companies}

Micheline Gaia Hoffmann

UDESC - Universidade do Estado de Santa Catarina - Brasil michelinegaia@gmail.com

Eliza Coral

Fundação Certi - Brasil ecl@certi.org.br

Eduardo Jara

UDESC - Universidade do Estado de Santa Catarina - Brasil eduardo.jara@udesc.br

Recebido em 13 de agosto de 2013. Alterado em 15 de setembro de 2014. Aprovado em 30 de setembro de 2014.

Editor Responsável: Edson Roberto Scharf, Dr.

Processo de avaliação por double blind review

\section{Resumo}

Este artigo é resultado de pesquisa quantitativa que examina as relações entre P\&D (gastos, qualificação dos colaboradores e práticas de colaboração externa), geração de patentes e exportação em empresas brasileiras ativamente inovadoras. Foram testadas sete hipóteses de relação entre as variáveis a partir de dados coletados junto a empresas participantes do Prêmio FINEP de Inovação 2010. A amostra, não probabilística, foi composta pelas 471 empresas participantes, distribuídas em 18 setores em cinco regiões brasileiras. Os resultados mostram que nestas empresas há relação entre os investimentos em $\mathrm{P} \& \mathrm{D}$, o número de patentes e a capacidade de exportação. Viu-se ainda que a relação entre gastos em P\&D e patentes, assim como entre a existência de parcerias com universidades e patentes, é fraca.
Adicionalmente, nas empresas pesquisadas, quanto maior a qualificação dos colaboradores atuantes em P\&D, maior o número de patentes geradas.

Palavras-chave: Inovação. P\&D. Patentes. Exportação.
Abstract
This paper is the outcome of quantitative research that examines the relationship between $R \& D$ (expenditures, personnel training and practices of external collaboration), patent generation and exporting in Brazilian companies which are identified as innovative. The research tested 07 hypotheses for the relationship between variables, using data collected from the companies that participated in the FINEP Prize for Innovation 2010. The sample is non-probabilistic and counted 
on 471 companies, distributed over 18 sectors and 5 regions of Brazil. The results show that there is a relationship between the investments in $R \& D$, the number of patents generated and the capacity of exporting in the researched companies. The research also shows that there is a weak relationship between $R \& D$ expenditures and patents, as well as between partnership with universities and patents. In addition, in the researched companies, the more training the personnel working on $R \& D$ receive, the more patents that are generated.

Keywords: Innovation. R\&D. Patents. Exporting.

\section{Introdução}

No contexto competitivo global, a capacidade de inovação tem sido apontada como um dos principais requisitos para a conquista de vantagem competitiva pelas empresas, sobretudo no contexto internacional (PAVITT, 1982; CHRISTENSEN, 2000; SMITH et al., 2008; CROSSAN; APAYDIN, 2010). Frequentemente, a capacidade para inovar é associada à estratégia empresarial. A clareza estratégica em relação ao papel da inovação é considerada fundamental para que ela aconteça (QUINN, 1980; ZUNIGA; CRESPI, 2013).

Por outro lado, a inovação como estratégia de competitividade requer a criação de competências internas capazes de gerar e sustentar vantagem competitiva. Nesse sentido, as empresas desenvolvem, individualmente ou de forma colaborativa, atividades de inovação, que compreendem as etapas científicas, tecnológicas, organizacionais, financeiras e comerciais que podem conduzir à implementação de inovações (OCDE; FINEP, 2005). Nesse amplo espectro de atividades, aquelas relacionadas à geração, apropriação e proteção de conhecimento, ocupam posição de destaque. Afinal, o conhecimento está na base da inovação (CHRISTENSEN, 2000; SCHUMPETER, 1982).

Nesse contexto, o investimento em
Pesquisa e Desenvolvimento (P\&D) constitui um indicador consagrado mundialmente para medir os esforços de inovação de empresas, regiões e países. O mesmo ocorre com o número de patentes geradas. Estes dois indicadores são frequentemente incorporados em estudos que avaliam dinamismo tecnológico (BELL e PAVITT, 1993; OCDE; FINEP, 2005; SMITH et al., 2008; ZUNIGA; CRESPI, 2013; FAN, GILLAN; YU, 2013).

Considerando-se a direção em que evolui o comércio internacional - segundo dados da ONUDI (2002), as exportações de produtos de alta e média tecnologia crescem mais rápido que a exportação de outras manufaturas, a ponto de produtos complexos representarem dois terços das exportações do mundo - pode-se inferir que, na busca por ampliar sua capacidade de exportação, as empresas podem ter no investimento em inovação um aliado. Os países em que tem ocorrido expansão significativa da parcela dos produtos de alta tecnologia nas exportações apresentaram, no passado, uma intensificação do esforço tecnológico. Vários autores como, por exemplo, Pavitt (1982), Becker e Dietz (2004) e Zuniga e Crespi (2013) discutem esta relação entre $\mathrm{P} \& \mathrm{D}$, patentes e performance no comércio exterior.

Estes fatores justificam a disseminação de políticas públicas que fomentam a elevação de gastos com P\&D, a maior integração entre instituições de pesquisa e o setor produtivo, o aumento do número de patentes, dentre outras estratégias, como forma de promover o fortalecimento da competitividade da economia nos mercados internacionais. Pressupostos desta natureza guiam políticas públicas em países desenvolvidos e recentemente têm se consolidado também no Brasil, assim como em outros países em desenvolvimento (FURTADO; SUZIGAN, 2006; IEDI, 2005; IEDI, 2011; PLAZA, SANTOS; CARRARO, 2009). 
Assim, é relevante ao tomador de decisão, tanto no contexto da empresa, quanto no âmbito da política pública, compreender as relações existentes entre os diversos tipos de esforços empreendidos para ampliar a capacidade de inovação e seus impactos finais. Uma revisão sistemática da literatura realizada por Smith et al. (2008) demonstra que muitos estudos apontam os fatores que exercem influência sobre a capacidade de inovação das empresas. Entretanto, poucos exploram como estes fatores se relacionam mutuamente. Crossan e Apaydin (2010), em uma revisão sistemática mais recente, demonstraram a importância de se compreender as relações entre os fatores que caracterizam a inovação enquanto processo e aqueles que caracterizam sua dimensão de resultado.

Neste artigo, discute-se as relações entre atividades de inovação (especificamente o volume de recursos investidos em P\&D, a qualificação dos colaboradores em $P \& D$ e as práticas de colaboração em $P \& D$ ), geração de patentes e capacidade de exportação em empresas brasileiras ativamente inovadoras. Especificamente, são investigadas as empresas que participaram do Prêmio FINEP de Inovação 2010.

$\mathrm{Na}$ próxima seção, apresenta-se a fundamentação teórica a partir da qual foram formuladas as hipóteses do estudo. $\mathrm{Na}$ seguinte, são detalhados os procedimentos metodológicos. A seguir, são apresentados e analisados os resultados e, finalmente, são esboçadas conclusões do estudo e apontadas algumas limitações.

\section{Relações entre P\&D, patentes e inovação}

O ato de inovar está associado a um arcabouço de novos conhecimentos e de conhecimentos previamente existentes, reunidos e combinados com vistas ao desenvolvimento e implantação de novas tecnologias, de tal forma que possam agregar valor à economia. Esta perspectiva conceitual, associada ao trabalho de Schumpeter (1982) e adotada pelo Manual de Oslo (OCDE; FINEP, 2005) evidencia a importância do conhecimento no processo de inovação.

Embora evidências demonstrem que grande parte das inovações não ocorre de pesquisa, mas da aprendizagem que decorre da experiência (LUNDVAL, 1992), uma alternativa consagrada para a produção de conhecimento com vistas à inovação são as atividades de Pesquisa e Desenvolvimento. Elas compreendem, segundo o Manual de Frascati (OECD, 2002): a pesquisa básica, a pesquisa aplicada e o desenvolvimento experimental.

Para Zuniga e Crespi (2013), parte relevante da estratégia de inovação de uma empresa está relacionada à decisão de investimento em $\mathrm{P} \& \mathrm{D}$, embora a forma como as firmas inovam e se engajam na corrida tecnológica não esteja apenas relacionada a esse fator. Os autores juntam-se a Bell e Pavitt (1993) ao destacar a importância de se discutir esse assunto com foco no contexto particular de países em desenvolvimento. Nestes países, a tradição de copiar ou importar tecnologia historicamente se sobrepõe à decisão de realizar investimento próprio em Pesquisa \& Desenvolvimento. Como concluem Fan, Gillion e Yu (2013), a importância das atividades de $\mathrm{P} \& \mathrm{D}$ está associada ao fato de que elas constituem um input crítico à inovação e, por conseguinte, ao crescimento econômico.

Além do volume de gasto, outro insumo das atividades de P\&D é a qualificação do pessoal. Os estudos de Zuniga e Crespi (2013) também encontram evidências recentes de que a qualificação dos trabalhadores exerce influência sobre a capacidade de inovação.

Além dos investimentos próprios em $P \& D$, cumpre observar que, na medida 
em que o conhecimento se torna mais complexo, aumenta a importância das interações entre empresas e outras organizações como uma forma de adquirir conhecimento especializado. Segundo o Manual de Oslo (OCDE; FINEP, 2005), a visão da inovação sob uma perspectiva baseada em conhecimento concentra-se em processos interativos através dos quais o conhecimento é criado e trocado dentro das empresas e entre empresas e outras organizações.

Um sintético resgate da evolução dos modelos de inovação no tempo - do modelo linear (STOKES, 2005) ao sistêmico (OCDE; FINEP, 2005), passando pelo modelo do elo de cadeia (KLINE; ROSENBERG, 1986) - demonstra o reconhecimento de que a inovação envolve insumos multifacetados e a influência simultânea de fatores organizacionais, institucionais e econômicos. Ao discutir o conceito de sistemas nacionais de inovação, Freeman (1995), explica que a inovação é um processo interativo em que a empresa, além de adquirir conhecimentos a partir de sua própria experiência nas etapas de desenho, desenvolvimento, produção e comercialização, também está em processo permanente de aprendizagem. Isso ocorre em função de suas relações com diversas fontes externas, como fornecedores, clientes, concorrentes, consultores, universidades e centros de pesquisa. Essas relações geram um processo complexo e interativo, que ultrapassa a compreensão da inovação sob uma premissa mecanicista, baseada em modelos sequenciais e lineares (TÖDLING; KAUFMANN, 2002). A interatividade do modelo não linear referese não apenas às colaborações internas entre os diversos departamentos que compõem a empresa, mas também, à interação da empresa com diferentes atores de seu entorno.

$$
\text { Zuniga e Crespi }
$$

demonstram que o P\&D externo, quer seja por meio de aquisições ou de colaborações, contribui para o aumento da produtividade da pesquisa interna. Tidd, Bessant e Pavitt (2008) também apresentam evidências neste sentido. Por outro lado, Zuniga e Crespi (2013) constataram que os investimentos internos são relevantes inclusive para desenvolver a capacidade de absorção que proporcionará a efetividade na busca, seleção, assimilação e adoção de tecnologias geradas externamente. Assim, estratégias mistas - P\&D interno e externo - têm efeitos complementares sobre a capacidade de inovação. Isso ajuda a explicar os achados de Becker e Dietz (2004), segundo os quais quanto mais uma empresa investe internamente em $\mathrm{P} \& \mathrm{D}$, mais ela mantêm laços de colaboração externa. Dentre os parceiros externos, González-Maestre e Granero (2013) exploram particularmente $\mathrm{o}$ caráter complementar da pesquisa realizada em universidades e instituições científicas aos esforços próprios em P\&D. Contrariando os pressupostos, estes autores constataram que o P\&D público realizado por instituições acadêmicas não tem impacto relevante na produtividade industrial. Sua influência é indireta, complementando e estimulando os gastos internos.

Seja como for, a partir dos esforços dedicados em P\&D, seja internamente, seja por meio de encomendas ou colaborações externas, espera-se, como resultado, que haja uma ampliação da capacidade para se gerar inovação.

Um importante indicador para avaliar a capacidade inovativa e o dinamismo tecnológico de uma empresa, bem como de regiões e de países, é o número de patentes geradas. Segundo o Manual de Oslo (OCDE; FINEP, 2005), duas famílias básicas de indicadores de Ciência e Tecnologia são diretamente relevantes para a mensuração da inovação: recursos direcionados a $\mathrm{P} \& \mathrm{D}$ e estatísticas de patentes. Também para Pavitt (1982), estatísticas de $\mathrm{P} \& \mathrm{D}$ e de patentes são direcionadores importantes em relação ao esforço e à direção das atividades de 
inovação nas empresas. Fan, Gillion e Yu (2013) posicionam a patente, enquanto forma de proteção de propriedade intelectual, como uma maneira de as empresas capturarem os ganhos de seus investimentos em $\mathrm{P} \& \mathrm{D}$ e de não perdê-los para competidores. Por isso, a possibilidade de proteção afeta diretamente a decisão de mais investimento em inovação. No setor de serviços, em particular, a dificuldade intrínseca à proteção de propriedade intelectual é apontada como uma das principais barreiras à alocação de recursos em inovação pelas empresas. A escassez de mecanismos de proteção é utilizada por vários autores também para explicar os baixos graus de colaboração entre empresas de serviços e parceiros externos (MENTION, 2011).

Embora a literatura explore a relação entre atividades de $\mathrm{P} \& \mathrm{D}$ e patentes, essa relação nem sempre será direta. Uma explicação está associada ao fato de que os resultados de $P \& D$ não necessariamente atendem os critérios de patenteabilidade. Além disso, formas alternativas de proteção da propriedade intelectual gerada podem ser adotadas. É o caso da opção pelo segredo industrial. Em mercados caracterizados por fortes barreiras de entrada, também a decisão pela patente pode ficar em segundo plano (PAVITT, 1982). São situações que explicam o fato de nem sempre o volume de patentes crescer proporcionalmente aos gastos em $\mathrm{P} \& \mathrm{D}$, o que requer o cuidado no uso destes indicadores.

De todo modo, estudos diversos confirmam a relação entre estas duas variáveis com a performance da empresa no que tange sua capacidade de exportação. Este aspecto será abordado na seção a seguir.

\section{P\&D, patentes e exportação}

Vários autores discutem a importância da capacidade de inovação sobre a performance das empresas. Crossan e Apaydin (2010), por exemplo, apontam a capacidade de inovação como o principal fator determinante da performance. Em um estudo que apresenta ampla revisão da literatura sobre inovação, eles observaram que diferentes autores usam diversas medidas de performance. Dentre elas, pode-se destacar: a lucratividade; o volume de vendas; a venda por empregado; o crescimento do número de emprego e a fatia de mercado. Já Nybakk e Jensen (2012) dedicam-se a explorar como a inovação influencia a performance financeira da empresa. $\mathrm{O}$ Manual de Oslo (OCDE; FINEP, 2005) vai além dos muros das empresas e discute impactos no âmbito industrial e, também, nacional. Nesse sentido, um dos fatores destacados corresponde ao aumento da competitividade internacional (das empresas e dos países) que pode decorrer da intensificação da capacidade de inovação.

Pavitt (1982) classifica como lugar comum a associação entre inovação e competitividade da indústria, crescimento econômico e mudança social. Da mesma forma, para ele, a correlação entre inovação e estabelecimento de vantagem competitiva internacional não é novidade. Ainda assim, este autor defende que são necessários estudos capazes de identificar como essas relações se comportam em diferentes firmas, indústrias e países, em diferentes períodos. Sobretudo, destaca a importância de se estudar as peculiaridades inerentes aos países menos desenvolvidos frente ao desafio de inovar. Nesse contexto, torna-se relevante o desenvolvimento de pesquisas focadas nessa temática no Brasil, que segundo o Índice Global de Competitividade (GCI), ocupa a $56^{\mathrm{a}}$ posição em um ranking de 143 países (SCHWAB, 2014). Feitas as ressalvas, o autor apresenta o resultado de pesquisas que relacionam investimentos 
em P\&D, geração de patentes e performance em exportação. Conclui que os dois primeiros são fatores determinantes da competitividade em exportação numa ampla gama de setores industriais.

Outros estudos também verificaram resultados consistentes quanto à relação positiva entre a inovação e a busca por mercados externos. Em Mais et al. (2010), por exemplo, são apresentados casos brasileiros que corroboram esta hipótese. Becker e Dietz (2004) também encontraram relação positiva entre investimento em $P \& D$ e exportação. Nas empresas por eles estudadas, quanto maior a parcela das vendas internacionais no total, maior o investimento em P\&D. Adicionalmente, estes autores constatam que os resultados em geração de produtos inovadores e, por conseguinte em exportação, são diretamente proporcionais à cooperação com parceiros externos, tais como fornecedores, clientes, concorrentes, universidades e institutos de pesquisa. A quantidade e a diversificação das fontes de cooperação afetam diretamente os outputs esperados do processo de inovação. Mais recentemente, Oura e Zilber (2014) desenvolveram estudo que integra as variáveis capacidade de inovação, experiência internacional e suas contribuições para o desempenho exportador num modelo teórico voltado à realidade das micro e pequenas empresas de países emergentes.

Existe uma tendência evolutiva das políticas públicas no Brasil de incentivo às atividades de P\&D como forma de impulsionar a inovação e, por meio desta, as exportações. A Política Industrial, Tecnológica e de Comércio Exterior (CASA CIVIL, 2003), o Plano de Desenvolvimento Produtivo (MDIC, 2008) e o Plano Brasil Maior (MDIC, 2011), por exemplo, adotam esta lógica. Nessa perspectiva, são importantes estudos capazes de evidenciar que estas categorias de fato exercem as influências mútuas esperadas. Para Sarewitz (2014), pesquisas que mapeiem o valor público gerado por estas políticas, são relevantes para apoiar a tomada decisão que influenciará novos investimentos públicos nessa matéria. Por outro lado, também podem apoiar o tomador de decisão nas empresas, cujo objetivo é maximizar a performance organizacional frente aos investimentos em atividades de inovação.

\section{Procedimentos metodológicos}

Inicialmente, cumpre apresentar a definição operacional das categorias de análise, respectivas variáveis e hipóteses da pesquisa. A categoria 'Pesquisa e Desenvolvimento' é constituída por três variáveis: (1) grau de qualificação dos pesquisadores envolvidos em atividades de P\&D na empresa; (2) investimentos em P\&D; e (3) colaborações em P\&D.

O Grau de Qualificação considera o número de técnicos, graduados, mestres e doutores atuantes em P\&D. Os Investimentos nas atividades de Pesquisa e Desenvolvimento consideram os valores absolutos investidos no período 2007 a 2009. E a Colaboração considera se a empresa desenvolveu ou não atividades de P\&D em parceria com Universidades e/ou Institutos de Pesquisa.

A categoria 'Patentes' é constituída pelo número de registros de patentes que a empresa possui no período de 2007 a 2009. E a categoria 'Exportação' considera se a empresa realizou exportações no período.

Com base na revisão teórica, foram formuladas as seguintes hipóteses:

01. Existe uma relação positiva entre o investimento em P\&D e a capacidade de geração de patentes;

02. Existe uma relação positiva entre o grau de qualificação dos colaboradores em P\&D e a capacidade de geração de patentes; 
03. Existe uma relação positiva entre o investimento em P\&D e a capacidade de exportação;

04. Existe uma relação positiva entre o grau de qualificação de colaboradores em P\&D e a capacidade de exportação;

05. Existe uma relação positiva entre a existência de parcerias com universidade e a capacidade de geração de patentes;

06. Existe uma relação positiva entre a existência de parcerias com universidade e a capacidade de exportação;

07. Existe uma relação positiva entre a capacidade de geração de patentes e a capacidade de exportação.

A presente pesquisa, de natureza quantitativa, testou as hipóteses anteriormente apresentadas a partir de dados coletados junto a 471 empresas participantes do Prêmio FINEP de inovação em 2010.

O Prêmio FINEP de Inovação foi criado em 1998 pelo Ministério de Ciência e Tecnologia para reconhecer e divulgar esforços inovadores realizados por empresas, instituições sem fins lucrativos e inventores brasileiros, desenvolvidos no Brasil e já aplicados no País ou no exterior. É considerado o mais importante instrumento de estímulo e reconhecimento à inovação no Brasil.

Para o Prêmio, empresas e instituições inovadoras são aquelas que desenvolvem soluções em forma de produtos, processos, metodologias e/ou serviços novos ou significativamente modificados. Desta forma, as empresas participantes constituem uma amostra da população de empresas brasileiras ativamente inovadoras. Segundo o Manual de Oslo, uma empresa ativamente inovadora

é aquela que realizou atividades de inovação durante o período de análise, incluindo as atividades em processo e abandonadas. Sob este conceito, empresas que tiveram atividades de inovação no período analisado, independentemente de sua atividade ter resultado na implementação de uma inovação, são empresas ativamente inovadoras. (OCDE; FINEP, 2005, p. 71).

Assim, o desenho amostral da pesquisa - não probabilístico - resolve um problema abordado na PINTEC 2008 (IBGE, 2010), onde foi apontado que desenhos tradicionais baseados em amostras aleatórias podem resultar em amostras que não representam adequadamente a fração da população de empresas ativamente inovadoras.

Do ponto de vista geográfico, a amostra contempla empresas das cinco regiões brasileiras. Os setores envolvidos, de acordo com a CNAE 2.0, foram: Agricultura, Pecuária e Serviços Relacionados; Fabricação de Produtos Alimentícios; Fabricação de Produtos Têxteis; Fabricação de Produtos Químicos; Fabricação de Produtos Farmoquímicos e Farmacêuticos; Metalurgia; Fabricação de Produtos de Informática, Produtos Eletrônicos e Ópticos; Fabricação de Máquinas, Aparelhos e Materiais Elétricos; Fabricação de Máquinas e Equipamentos; Fabricação de Móveis; Eletricidade, Gás e outras Utilidades; Construção de Edifícios; Telecomunicações; Atividades dos Serviços de Tecnologia da Informação; Atividades de Sedes de Empresas e de Consultoria em Gestão Empresarial; Serviços de Arquitetura e Engenharia; Educação e Atividades de Atenção à Saúde Humana.

Os dados foram coletados por meio dos formulários preenchidos pelas empresas como requisito à participação no Prêmio.

Para identificar correlação entre as variáveis quantitativas (número de patentes e investimento em $\mathrm{P} \& \mathrm{D}$; número de pesquisadores em $\mathrm{P} \& \mathrm{D}$ por grau de qualificação), foi realizada análise do 
coeficiente de correlação de Pearson. Com uso deste coeficiente, identificou-se o grau de relação entre as variáveis analisadas. "Quando duas variáveis apresentam uma correlação estatisticamente significativa, diz-se que existe uma dependência entre elas. A dependência pode ser positiva ou negativa, conforme seja o coeficiente de correlação." (BISQUERRA; SARRIERA; MARTÍNEZ, 2004, p. 145). Já na análise das variáveis qualitativas (exportação e parceria com universidade) foi utilizado o teste qui-quadrado para verificar independência entre elas.

O teste qui-quadrado é o teste estatístico mais antigo e um dos mais usados em pesquisa social. É um método que permite testar a significância da associação entre duas variáveis qualitativas, como também, comparar (no sentido de teste de significância) duas ou mais amostras, quando os resultados da variável resposta estão dispostos em categorias. (BARBETTA, 2008, p. 228).

\section{Apresentação dos resultados}

Foram realizados os testes estatísticos de qui-quadrado, medidas simétricas e correlações com a amostra de dados para confirmar as hipóteses delineadas na pesquisa. Os resultados são apresentados a seguir.

a) Hipótese 01: Existe uma relação positiva entre o investimento em P\&D sobre a capacidade de geração de patentes

Ao cruzar as variáveis quantitativas, não foram encontradas evidências de correlação entre as variáveis investimento em $P \& D$ e geração de patentes, com $r=-0,005$ e valor $p=0,916$.

Entretanto, ao se tratar a variável 'número de patentes' como uma variável qualitativa, assumindo como possibilidade de resposta, 'TER' ou 'NÃO TER' patentes, encontra-se uma relação positiva. Essa constatação baseou-se num teste não paramétrico para investigar o coeficiente $\rho$ de Spearman, que evidencia a correlação entre investimentos em $P \& D$ e ter ou não patentes, com $\rho=0,187$ e valor-p $<0,001$. Embora o valor de $p$ e o coeficiente $\rho$ de Spearman sejam baixos, o resultado sugere uma relação positiva entre as variáveis.

Assim, para as empresas pesquisadas, o investimento em $\mathrm{P} \& \mathrm{D}$, apontado por Fan, Gillion e Yu (2013) e Zuniga e Crespi (2013) como importante input do processo de inovação, não constitui uma estratégia significativa para ampliar o número de patentes, enquanto resultado esperado. Cumpre destacar que esta constatação não sugere uma menor relevância do investimento em P\&D. Considerando-se as ressalvas vistas em Pavitt (1982), o fato de não se ter um ganho no volume de patentes geradas não permite concluir que os investimentos em P\&D sejam irrelevantes na geração de inovações. Resultados inovadores, mas não patenteáveis, opção por outras formas de proteção ou característica do mercado/setor, são fatores que podem explicar o não crescimento do número de patentes com o volume de recursos investidos em P\&D. Entretanto, estas facetas não foram investigadas na pesquisa.

b) Hipótese 02: Existe uma relação positiva entre o grau de qualificação dos colaboradores em $\mathrm{P} \& \mathrm{D}$ sobre a capacidade de geração de patentes

$\mathrm{O}$ número de patentes mostrou-se correlacionado de maneira positiva com o número de pesquisadores em $\mathrm{P} \& \mathrm{D}$ $(\mathrm{r}=0,154$ e valor- $\mathrm{p}=0,001)$. Neste caso, o grau de correlação é considerado fraco (BARBETTA, 2008).

Correlacionando-se a variável 'número de patentes' com 'quantidade de mestres e pós-graduados' e de 'doutores e 
PhDs, encontra-se relações significantes (mestres: $r=0,144$ e valor-p $=0,002$; doutores: $r=0,122$ e valor- $p=0,008)$. Isso indica que, quanto maior a qualificação dos colaboradores em P\&D, maior a capacidade da empresa para gerar patentes.
A Tabela 1 apresenta os resultados dos testes de correlação relativos às hipóteses 01 e 02.

Tabela 1 - Testes de correlação relativos às Hipóteses 01 e 02

\begin{tabular}{|c|c|c|c|c|c|c|}
\hline & & $\begin{array}{c}\text { Patentes_n } \\
\text { um }\end{array}$ & $\begin{array}{c}\text { Investimento_P } \\
\& D\end{array}$ & $\begin{array}{c}\text { Pesquisador_P } \\
\text { eD }\end{array}$ & $\begin{array}{l}\text { Mestre_e } \\
\text { Pos }\end{array}$ & $\begin{array}{c}\text { Doutor_PH } \\
\text { D }\end{array}$ \\
\hline \multirow[t]{3}{*}{ Patentes_num } & $\begin{array}{l}\text { Pearson } \\
\text { Correlation }\end{array}$ & 1 &,- 005 &, $154^{* *}$ &, $144^{* *}$ &, $122^{* *}$ \\
\hline & Sig. (2-tailed) & & ,916 & 001 & ,002 & ,008 \\
\hline & $\mathrm{N}$ & 471 & 471 & 471 & 471 & 471 \\
\hline \multirow[t]{3}{*}{ Investimento_P\&D } & $\begin{array}{l}\text { Pearson } \\
\text { Correlation }\end{array}$ &,- 005 & 1 &,- 002 & ,012 &,- 010 \\
\hline & Sig. (2-tailed) & ,916 & & ,962 & , 803 & ,827 \\
\hline & $\mathrm{N}$ & 471 & 471 & 471 & 471 & 471 \\
\hline \multirow[t]{3}{*}{ Pesquisador_PeD } & $\begin{array}{l}\text { Pearson } \\
\text { Correlation }\end{array}$ &, $154^{* * *}$ &,- 002 & 1 &, $902^{* * *}$ & ,678** \\
\hline & Sig. (2-tailed) & 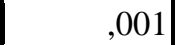 & ,962 & & ,000 & ,000 \\
\hline & $\mathrm{N}$ & 471 & 471 & 471 & 471 & 471 \\
\hline \multirow[t]{3}{*}{ Mestre_e_Pós } & $\begin{array}{l}\text { Pearson } \\
\text { Correlation }\end{array}$ &, $144^{* *}$ & ,012 & , $902^{* *}$ & 1 & ,643** \\
\hline & Sig. (2-tailed) & ,002 & ,803 &, 000 & & ,000 \\
\hline & $\mathrm{N}$ & 471 & 471 & 471 & 471 & 471 \\
\hline \multirow[t]{3}{*}{ Doutor_PHD } & $\begin{array}{l}\text { Pearson } \\
\text { Correlation }\end{array}$ &, $122^{* *}$ &,- 010 & ,678** & ,643** & 1 \\
\hline & Sig. (2-tailed) & ,008 & ,827 & ,000 & ,000 & \\
\hline & $\mathrm{N}$ & 471 & 471 & 471 & 471 & 471 \\
\hline
\end{tabular}

**. Correlation is significant at the 0.01 level (2-tailed).

Fonte: Elaborado pelos Autores.

O resultado deste teste sugere que as políticas públicas que apostam na qualificação de quadros para Pesquisa e Desenvolvimento, em particular aquelas que incentivam a colocação de mestres e doutores em atividades de P\&D nas empresas, podem esperar, como resultado, melhorias no número de patentes geradas.

c) Hipótese 03: Existe uma relação positiva entre o investimento em
P\&D sobre a capacidade de exportação

Os testes demonstraram que existem relações significantes entre o investimento em P\&D e a capacidade de exportação da empresa, com $\rho$ de Spearman $=0,251$ e valor-p $<0,001$, o que indica que o investimento em atividades de pesquisa para o desenvolvimento de novos produtos e soluções contribui para aumentar a capacidade de exportação das 
empresas estudadas. Estas conclusões corroboram os achados de Pavitt (1982) e, Becker e Ditz (2004), vistos anteriormente.

d) Hipótese 04: Existe uma relação positiva entre o grau de qualificação de colaboradores em P\&D sobre a capacidade de exportação
Os resultados dos valores de $\mathrm{r}$ e $\mathrm{p}$ confirmaram a hipótese 04, existindo relação positiva entre a qualificação do quadro de colaboradores e a capacidade de exportação das empresas.

A Tabela 2 apresenta os resultados dos testes para a hipótese 04, relacionando a capacidade de exportação com o grau de qualificação dos colaboradores em P\&D.

Tabela 2 - Testes de correlação relativos à Hipótese 04

\begin{tabular}{ll|r|r|r|r}
\hline & & Exporta & $\begin{array}{c}\text { Doutor_P } \\
\text { HD }\end{array}$ & $\begin{array}{c}\text { Mestre_e } \\
\text { _Pós }\end{array}$ & $\begin{array}{c}\text { Pesquisador_P } \\
\text { \&D }\end{array}$ \\
\hline Spearman's rho Exporta & Correlation & 1,000 &, $098^{*}$ &, $215^{* * *}$ &, $253^{* * *}$ \\
& Coefficient & & & & \\
& Sig. (2-tailed) & & 033 &, 000 &, 000 \\
& $\mathrm{~N}$ & 471 & 471 & 471 & 471 \\
\hline
\end{tabular}

*. Correlation is significant at the 0.05 level (2-tailed).

**. Correlation is significant at the 0.01 level (2-tailed).

Fonte: Elaborado pelos Autores.

Este resultado, juntamente com o da hipótese 2, sugere um resgate da teoria schumpeteriana, ao reiterar a importância do conhecimento aos resultados do processo de inovação e, destes, ao desempenho competitivo da empresa. Considerando-se, ainda, o resultado da hipótese 3, pode-se apontar para a coerência de decisões, quer seja no contexto da empresa, quer seja no contexto das políticas públicas, que esperem incremento da performance no mercado internacional como resultado de esforços de P\&D.

e) Hipótese 05: Existe uma relação positiva entre a existência de parcerias com universidade e a capacidade de geração de patentes

Das 471 empresas pesquisadas, $72 \%$ afirmaram terem algum tipo de parceria com universidades para o desenvolvimento de produtos e processos inovadores. Destas, 33\% possuem patentes registradas.

As parcerias com universidades não mostraram relação significativa como o número de patentes registradas, apresentando para esta relação valor $\mathrm{p}=0,665$. Portanto, a hipótese 05 não foi confirmada.

A Tabela 3 apresenta os resultados do teste qui-quadrado para a hipótese 05 .

Tabela 3 - Teste de qui-quadrado relativo à Hipótese 05

\begin{tabular}{|c|c|c|c|c|c|}
\hline & Value & df & $\begin{array}{l}\text { Asymp. Sig. (2- } \\
\text { sided) }\end{array}$ & $\begin{array}{l}\text { Exact Sig. (2- } \\
\text { sided) }\end{array}$ & $\begin{array}{l}\text { Exact Sig. } \\
\text { (1-sided) }\end{array}$ \\
\hline Pearson Chi-Square &, $187^{\mathrm{a}}$ & 1 & ,665 & & \\
\hline Continuity Correction ${ }^{\mathrm{b}}$ & , 108 & 1 &, 743 & & \\
\hline Likelihood Ratio &, 187 & 1 & ,665 & & \\
\hline Fisher's Exact Test & & & & 678 & ,372 \\
\hline
\end{tabular}


Linear-by-Linear Association $\mathrm{N}$ of Valid Cases
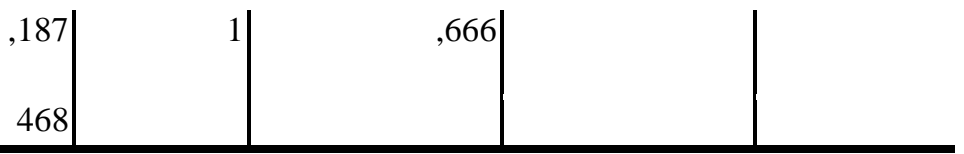

a. 0 cells $(, 0 \%)$ have expected count less than 5 . The minimum expected count is 58,07.

b.Computed only for a $2 \times 2$ table

Fonte: Elaborado pelos Autores.

O Gráfico de barra representado na Figura 1 confirma que não há diferença significativa em termos proporcionais ao se relacionar número de patentes com o fato de haver ou não parceria com universidades.

Figura 1 - Relação entre Patentes e Parcerias com Universidades e Institutos de Pesquisa

\section{Bar Chart}

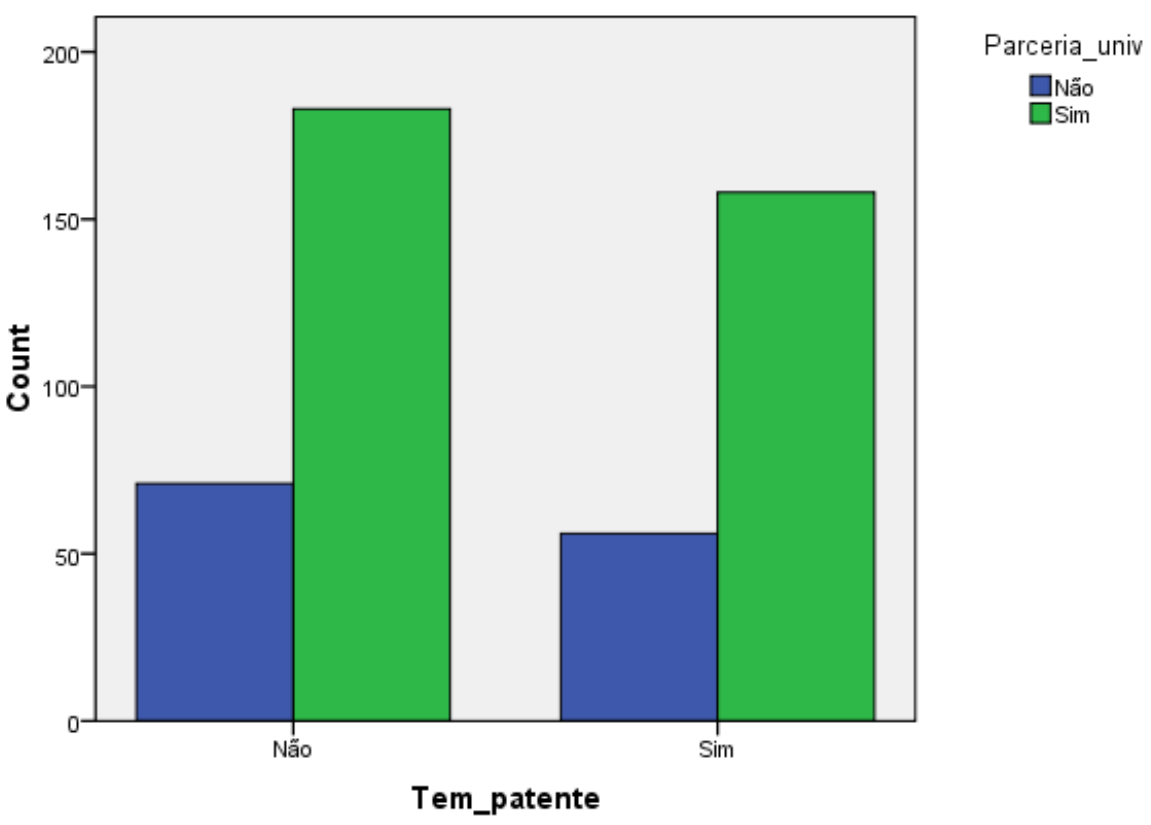

Fonte: Elaborado pelos Autores.

O resultado desse teste de hipótese parece estar em dissonância com achados mencionados na revisão da literatura.Viuse em Becker e Dietz (2004), Tidd, Bessant e Pavitt (2008), Zuniga e Crespi (2013) e em González-Maestre e Granero (2013), a potencialidade das parcerias externas, sobretudo com universidades e institutos de pesquisa, para o incremento da capacidade de inovação das empresas. Com isso, espera-se que um dos resultados do estabelecimento de parcerias seja o impacto na geração de patentes. A inexistência dessa relação evidenciada no teste realizado nesta pesquisa pode ser explicada com base nos argumentos já apresentados na hipótese 1 , que relativiza a importância da patente como indicador de resultado do processo de inovação. Por outro lado, considerando os resultados da hipótese 2, que comprovou uma relação significativa entre qualificação em $P \& D$ e 
geração de patentes, o estudo encontrou um limite na busca por conclusões. Por isso, sugere-se maior investigação em torno dessa questão em particular em pesquisas futuras. As dificuldades associadas à cooperação universidadeempresa, evidenciadas por Perkmann et al (2013), podem explicar o resultado desse teste. Mas a pesquisa não investigou estas possibilidades, de forma que não é possível apresentar explicações conclusivas.

f) Hipótese 06: Existe uma relação positiva entre a existência de parcerias com universidade e a capacidade de exportação

Conforme demonstrado nas Tabelas 4 e 5, existe evidência estatística de confirmação desta hipótese, indicando algum grau de dependência entre as variáveis analisadas, pois o teste quiquadrado para as variáveis 'Exportação' e 'Parceria com Universidades' apresentou coeficiente de contingência 0,116 e valor-p $=0,011$.

Tabela 4 - Teste qui-quadrado para a hipótese 06

\begin{tabular}{|c|c|c|c|c|c|}
\hline & Value & df & $\begin{array}{l}\text { Asymp. Sig. (2- } \\
\text { sided) }\end{array}$ & $\begin{array}{l}\text { Exact Sig. (2- } \\
\text { sided) }\end{array}$ & $\begin{array}{l}\text { Exact Sig. (1- } \\
\text { sided) }\end{array}$ \\
\hline Pearson Chi-Square & $6,401^{\mathrm{a}}$ & 1 &, 011 & \multirow{6}{*}{,013 } & \multirow{6}{*}{, 007} \\
\hline Continuity Correction ${ }^{\mathrm{b}}$ & 5,728 & 1 &, 017 & & \\
\hline Likelihood Ratio & 6,996 & 1 &, 008 & & \\
\hline Fisher's Exact Test & & & & & \\
\hline $\begin{array}{l}\text { Linear-by-Linear } \\
\text { Association }\end{array}$ & 6,388 & 1 &, 011 & & \\
\hline $\mathrm{N}$ of Valid Cases & 468 & & & & \\
\hline
\end{tabular}

a. 0 cells $(0 \%)$ have expected count less than 5 . The minimum expected count is 22,25.

b. Computed only for a $2 \times 2$ table

Fonte: Elaborado pelos Autores.

As evidências estatísticas obtidas na análise sugerem um impacto positivo das parcerias com o ambiente acadêmico sobre a competitividade das empresas, à medida que impactam positivamente a exportação. Por outro lado, o conjunto dos dados apresentados nas hipóteses anteriormente apresentadas indica que os investimentos em $P \& D$, sejam em estrutura interna, sejam em parcerias externas, não exercem impacto sobre a capacidade de inovação na forma de patentes. Essas constatações remetem à orientação de se relativizar a importância da patente como indicador de resultado prioritário para avalição dos resultados de processos de inovação. Novamente, como demonstrado por Pavitt (1982) e reforçado por Oura e Zilber (2014), embora amplamente adotado, esse indicador resguarda uma série de imperfeições, não constituindo uma medida completa para verificar capacidade de inovação.

Tabela 5 - Medidas simétricas para a hipótese 06

\begin{tabular}{lr|r|r}
\hline & \multicolumn{1}{|c|}{ Value } & Approx. Sig. \\
\hline Nominal by Nominal Contingency Coefficient &, 116 &, 011 \\
N of Valid Cases & & 468 & \\
\hline
\end{tabular}

Fonte: Elaborado pelos Autores. 
g) Hipótese 07: Existe uma relação positiva entre a capacidade de geração de patentes e a capacidade de exportação

$\mathrm{O}$ teste qui-quadrado confirmou esta hipótese, indicando existência de algum grau de dependência entre estas variáveis com coeficiente de contingência 0,114 e valor-p 0,012. Assim, embora a geração de patentes não constitua um indicador absoluto para indicar a eficácia dos esforços de pesquisa, apresenta relação direta com a capacidade de exportação das empresas pesquisadas.

\section{Considerações finais}

Este artigo discutiu, a partir de uma pesquisa quantitativa, as relações entre pesquisa e desenvolvimento, geração de patentes e exportação em empresas brasileiras ativamente inovadoras.

A título de conclusão, merecem destaque as hipóteses que envolveram a capacidade para geração de patentes como resultado do processo de inovação. Contrariando os pressupostos sugeridos pela base teórica, investimentos em P\&D e parcerias com universidades não estão resultando em patentes para as empresas pesquisadas. Estes resultados corroboram os estudos que apontam o baixo número de patentes depositadas por empresas brasileiras (CNI, 2014).

Adicionalmente, os resultados mostraram que quanto maior a capacitação dos colaboradores que atuam em P\&D, maior a geração de patentes. Ou seja, para um alto grau de capacitação, especialmente doutores, a correlação entre as variáveis é forte. Este resultado é coerente com a perspectiva de que o conhecimento e a capacidade de pesquisa estão diretamente associados à capacidade de gerar novos conceitos e combinações. Além disso, viuse, ainda, que há forte correlação entre capacidade de geração de patentes e exportação.

Estes resultados remetem, por um lado, a importância das patentes para a competitividade das empresas e, consequentemente, para o desenvolvimento econômico do país. Por outro, sugerem que investimentos em $\mathrm{P} \& \mathrm{D}$, quer seja dentro das empresas, quer seja em parcerias com universidades e institutos de pesquisa, não constituem uma boa estratégia de promoção da inovação, na medida em que eles não resultam em ampliação no número de patentes.

$\mathrm{Na}$ análise dos dados, encontrou-se explicação para esse fenômeno em Pavitt (1984), que já discutiu as imperfeições da patente como indicador de desempenho do processo de inovação. Assim, um dos aspectos a destacar, ao final deste trabalho, é exatamente a necessidade de se relativizar a ênfase a esta medida. Resultados dos investimentos em P\&D podem gerar impactos relevantes na performance das empresas sem passar pela patente como mecanismo de proteção. Isso pode se dar por diferentes razões, discutidas no artigo. No caso específico do Brasil, a CNI (2014) aponta como possíveis causas do baixo índice de depósito de patente, o tempo de processamento e a insegurança jurídica. Nesse caso, evidencia-se a necessidade de aperfeiçoamento do aparato administrativo e jurídico pertinente a essa matéria, além do reforço a políticas de incentivo para que as empresas protejam sua propriedade intelectual, a exemplo das boas práticas vistas nos países desenvolvidos (OCDE, 2008).

Outro aspecto relevante, é a aparente contradição entre duas hipóteses testadas. Viu-se que a maior qualificação dos colaboradores atuantes em P\&D dentro das empresas proporciona aumento na capacidade de geração de patentes. Paradoxalmente, as parcerias com universidades não impactam nesse indicador. Ora, se as instituições 
acadêmicas concentram o maior percentual de pesquisadores com alto grau de qualificação no Brasil (MCTI, 2012), essa deveria ser uma estratégia certeira na busca pela ampliação no número de patentes depositadas. Esse resultado traz à tona as dificuldades e os desafios intrínsecos à cooperação universidade-empresa, discutida por Perkmann et al (2013). A pesquisa não investigou as facetas do processo de cooperação das empresas em questão e, por isso, não é possível apresentar explicações conclusivas. Nesse sentido, recomenda-se a realização de pesquisas com foco nessa matéria.

Sugere-se, ainda, para pesquisas futuras, a inclusão de outras categorias de análise e variáveis em novos testes, que contemplem de forma mais abrangente as atividades de inovação e suas relações com a performance das empresas. Adicionalmente, como destacado por Pavitt (1982), são relevantes estudos que considerem as peculiaridades inerentes aos diferentes portes, setores e localização geográfica das empresas.

Para finalizar, cumpre discutir algumas limitações do estudo. Dentre elas, pode-se destacar as restrições intrínsecas às categorias de análise. Sabe-se que apesar de o P\&D desempenhar papel de grande importância no processo de inovação, muitas atividades inovadoras não são baseadas em P\&D. Como visto em Lundval (1992), por exemplo, grande parte das inovações não ocorre a partir de pesquisa, mas da aprendizagem que decorre da experiência. Adicionalmente, como demonstrado, a patente nem sempre se revela uma estratégia coerente e/ou necessária para a proteção de uma inovação.

Não obstante, $P \& D$ e número de patentes constituem indicadores de Ciência e Tecnologia internacionalmente adotados para a mensuração da inovação em empresas e países. Pavitt (1982) reconhece a existência de gaps nos sistemas de medidas que permitam a formulação de conclusões quanto a esta matéria. Por outro lado, considera que, de fato, as medidas estatísticas são imperfeitas (especialmente quando elas se limitam a indicadores muito concentrados). Ainda assim, sugere que talvez análises possam ser realizadas a partir do uso de uma variedade de medidas imperfeitas. Para o autor, pesquisas dessa natureza, especialmente quando transcendem microestudos e priorizam coleções de evidências, são necessários para orientar formuladores de políticas públicas. Espera-se que esse estudo tenha contribuído nesse sentido, para a realidade brasileira.

Outra importante limitação decorre do desenho amostral. Apesar das justificativas apresentadas, reconhecidas na própria PINTEC (IBGE, 2010), cumpre tomar o cuidado de alertar que os resultados deste estudo são aplicáveis ao universo das empresas participantes do Prêmio FINEP de Inovação, caracterizadas como empresas ativamente inovadoras (OCDE; FINEP, 2005). Não são, portanto, generalizáveis.

\section{Referências}

BARBETTA, P. A. Estatística aplicada às ciências sociais. Florianópolis: UFSC, 2008.

BECKER, W.; DIETZ, J. R\&D cooperation and innovation activities of firms - evidence for the German manufacturing industry. Research Policy, v. 33, p. 209-223, 2004.

BELL, M.; PAVITT, K. Technological accumulation and industrial growth: contrasts between developed and 
developing countries. Industrial and Corporate Change, v. 2, n. 2, p. 157-211, 1993.

BISQUERRA， R.; SARRIERA， J. C.; MARTIINEZ, F. Introdução à estatística: enfoque informático com o pacote SPSS. Porto Alegre: Artmed, 2004.

CASA CIVIL. Diretrizes de política industrial, tecnológica e de comércio exterior. Brasília, 2003.

CHRISTENSEN, C. M. The innovator's dilemma. New York: Harper Business, 2000 .

CNI, Propriedade Intelectual: as mudanças na indústria e a nova agenda. Brasília: CNI, 2014.

CROSSAN, M. M.; APAYDIN, M. A multidimensional framework of organizational innovation: a systematic review of the literature. Journal of Management Studies, v. 47, n. 6, set. 2010.

FAN, J. P. H.; GILLAN, S. L.; YU, X. Innovation or imitation? The role of intellectual property rights protections. Journal of Multinacional Financial Management, v. 23, p. 208-234, 2013.

FREEMAN, C. The national system of innovation in historical perspective. Cambridge Journal of Economics, v. 19, p. 5-24, 1995.

FURTADO, J.; SUZIGAN, W. Política industrial e desenvolvimento. Revista de Economia Política, São Paulo, v. 26, n. 2 (102), p.163-185, abr./jun. 2006.

GONZÁLEZ -MAESTRE, M.; GRANERO, L. M. Basic research and development in vertical markets. The Manchester School, v. 81, n. 3, p. 258275, jun. 2013.

IBGE. Pesquisa de inovação tecnológica 2008. Rio de Janeiro: IBGE, 2010.
IEDI. Diretrizes das políticas tecnológicas e de inovação: uma análise comparada. Brasília: IEDI, 2005.

IEDI. Indústria e política industrial, no Brasil e em outros países. Brasília: IEDI, 2011.

KLINE, S. ROSENBERG, N. An overview of innovation. In: LANDAU, $\mathrm{R}$. ROSENBERG, N. The positive sum strategy. Washington: National Academic of Press, 1986.

LUNDVALL, B. A. National systems of innovation: towards a theory of innovation and interactive learning. Londres: Pinter, 1992.

MAIS, I. et al. Importância das redes nos processos de inovação e internacionalização de empresas de base tecnológica. Revista de Administração e Inovação, São Paulo, v. 7, n. 1, p. 41-61, jan./mar. 2010.

MCTI. Pesquisadores e total de pessoas em pesquisa e desenvolvimento (P\&D) em equivalência de tempo integral, relacionados com pessoas ocupadas, de países selecionados, em anos mais recentes disponíveis. Brasília: MCTI, 2012. Disponível em: <http://www.mct.gov.br/index.php/content /view/8478.html>. Acesso em: 8 mar. 2012.

Política de desenvolvimento produtivo. Inovar e investir para sustentar o crescimento. Brasília: MCTI, [2008?]. Disponível em: <http://www.mdic.gov.br/pdp/arquivos/des tswf1212175349.pdf $>$. Acesso em: 05 set. 2012.

Brasil maior. Inovar para competir. Competir para crescer. Plano de Ação 2011-2014. Brasília: MCTI, [2011?]. Disponível em: <http://www.brasilmaior.mdic.gov.br/wpcontent/uploads/cartilha_brasilmaior.pdf $>$. Acesso em: 05 set. 2012. 
MENTION, Anne-Laure. Co-operation and co-opetition as open innovation practices in the service sector: which influence on innovation novelty? Technovation, n. 31, 44-53, 2011.

NYBAKK, E.; JENSSEN, J. I. Innovation strategy, working climate and financial performance in traditional manufacturing firms: an empirical analysis. International Journal of Innovation Management, v. 16, n. 2, apr. 2012.

OCDE; FINEP. Manual de Oslo: diretrizes para coleta e interpretação de dados sobre inovação. Brasília: OCDE/FINEP, 2005.

OECD. Compendium of patent statistics 2008. OECD, 2008.

OECD. Frascati Manual. Proposed standard practice for surveys on research and experimental development. OECD, 2002.

ONUDI. Informe sobre el desarrollo industrial correspondiente a 2002/2003. Viena, 2002.

OURA, M. M.; ZILBER, S. N. Inovação, experiência internacional e desempenho exportador de PMEs de países emergentes: proposição de um modelo teórico. Anais do XXXVIII Encontro da ANPAD. Rio de Janeiro: ANPAD, 2014.

PAVITT, K. R\&D, patenting and innovative activities: a statistical exploration. Research Policy, v. 11, p. 33$51,1982$.

PERKMANN, Markus et al. Academic engagement and commercialisation: a review of the literatura on universityindustry relations. Research Policy. 42, 423-442, 2013.

PLAZA, C. M. C. A; SANTOS, N.; CARRARO, F. Perspectivas da inovação tecnológica: análises comparativas da dinâmica tecnológica entre Brasil e Coréia.

Revista Eletrônica de Direito
Internacional, v. 4, 2009. Disponível em: $<$ http://www.cedin.com.br/revistaeletronic a>. Acesso em: 29 jan. 2012.

QUINN, James B. An incremental approach to strategic change. McKinsey Quarterly, v. 1, p. 34-52, winter 1980.

SAREWITZ, Daniel. Extracting and assessing the public values of science and innovation policies. In:Science of Science and Innovation Policy: Principal Investigators' Conference Summary. Washington: The National Academies Press, 2014.

SCHWAB, Klaus. The Global Competitiveness Report 2013-2014: Full Data Edition. Geneva: World Economic Forum, 2014. Disponível em : $<$ http://www3.weforum.org/docs/WEF_Gl obalCompetitivenessReport_2013-14.pdf> . Acesso em: 19 de setembro de2014.

SCHUMPETER, J. A. Teoria do desenvolvimento econômico. São Paulo: Abril Cultural, 1982.

SMITH et al. Factors influencing na organisation's ability to manage innovation: a structures literature review and conceptual model. International Journal of Innovation Management, v. 12, n. 4 , dec. 2008

STOKES, D. E. O quadrante de Pasteur: a ciência básica e a inovação tecnológica. Campinas: Unicamp, 2005.

TIDD, J.; BESSANT, J.; PAVITT, K. Gestão da inovação. Porto Alegre: Bookman, 2008.

TÖDTLING, F.; KAUFMANN, A. SMEs in Regional Innovation Systems and the role of innovation support. Journal of Technology Transfer, v. 27, p. 15-26, 2002.

ZUNIGA， P.; CRESPI, G. Innovation strategies and employment in Latina American firms. Structural Change and Economic Dynamics, v. 24, p. 1-17, 2013. 